\title{
The Hard Problem of Consciousness in the Light of Onto-Gnoseological Uncertainty
}

\section{EKATERINA NIKOLAEVNA GNATIK}

Peoples' Friendship University of Russia (RUDN University)

gnatik_en@rudn.university

ORCID: 0000-0002-2690-3035

\section{SERGEY ALEXANDROVICH LOKHOV}

Peoples' Friendship University of Russia (RUDN University)

lokhov_sa@rudn.university

ORCID: 0000-0002-9046-601X

\section{DMITRY VALERIEVICH MAMCHENKOV}

Peoples' Friendship University of Russia (RUDN University) mamchenkov_dv@rudn.university

ORCID: 0000-0003-0484-2232

\section{MARIA PETROVNA MATYUSHOVA}

Peoples' Friendship University of Russia (RUDN University) matyushova_mp@rudn.university

ORCID: 0000-0003-0585-8412

\begin{abstract}
Purpose: The main purpose of this article is to show that the paradigm of viewing the 'hard problem' of consciousness in analytic philosophy makes it a pseudo-problem rather than a 'hard problem'. The objectives of this research included showing the reasons for the authors' thesis, demonstrating the irreducibility of consciousness as a special layer of reality, and proposing a way to overcome these difficulties.
\end{abstract}

The publication was prepared with the support of the "RUDN University Program 5-100". Peoples' Friendship University of Russia (RUDN University), Address: h. 10, bld. 2, Miklukho-Maklaya St., 117198, Moscow, Russia. 
Design/methodology/approach: In this article, the 'hard problem' of consciousness is viewed from the standpoints of the transcendental-phenomenological and dialectical approaches and is analyzed through the prism of the principle of onto-gnoseological uncertainty.

Findings: It is shown that the way of formulating the 'hard problem' in the analytical philosophical tradition inevitably makes it a pseudo-problem. At the same time, with the consistent realization of the principle of onto-gnoseological uncertainty, the antinomy of solutions to the problems of consciousness is eliminated, which opens up a way to a productive solution of problems related to the interpretation of consciousness both in natural sciences and in philosophy.

Originality/value: This research reveals the methodological potential of applying the principle of onto-gnoseological uncertainty to the problems that arise in modern philosophy in connection with the achievements of natural sciences.

Keywords: hard problem of consciousness; consciousness and brain; subjective reality; qualia; onto-gnoseological uncertainty.

\section{Introduction}

Based on modern research in the field of the philosophy of consciousness and, at the same time, applying the transcendental-phenomenological and dialectical approaches to this problem, the authors of this research view the hard problem of consciousness in a completely new light. The methodology of analytical philosophy, which goes back to the works of L. Wittgenstein (1994) and B. Russel (1999), is based on the principle of logical analysis in the solution of philosophical problems. Nevertheless, logical analysis works well when reviewing 'easy' problems, i.e. problems that do not go beyond a single level of language, and their formulations do not require switching to a meta-language. When an analytic approach is applied to problems that cannot be expressed only in the object language, this leads to the emergence of semantic paradoxes, and to the emergence of 'hard' problems in the philosophical context. Unfortunately, analytic philosophy has never paid attention to the fact that it is the attempt to formulate the problem of consciousness by analytical methods that leads to paradoxes (as will be shown below), thereby making the problem of consciousness receives a 'hard' problem (Chalmers 1995; Horst 2014; Carruthers, Schier 2017a). 
The objective of this article is, first of all, to show that the very method of asking and resolving questions about consciousness in analytic philosophy inevitably turns it into a pseudo-problem (i.e. the problem that has a wrong wording, whose statements results in paradoxes). The authors of this research present four reasons and four ways of argumentation for revealing its pseudo nature. Secondly, they demonstrate that with the correct formulation of questions about consciousness (in which consciousness is viewed not as a completely unique phenomenon but as a form of the evolution of matter), it is possible to apply a constructive approach to the solution of the problems of consciousness. As such, the authors propose the principle of the onto-gnoseological uncertainty (Mamchenkov 2017).

\section{Literature Review}

Since the end of the $20^{\text {th }}$ century and to this day, the hard problem of consciousness has been one of the main themes of analytic philosophy. A great number of journals, collections, and monographs are published in the framework of the paradigm of the 'hard problem' (Menon 2014; Tsou 2014; McBride 2014; Smythies 2017; Smith, Whitaker 2014). However, when formulating the 'hard problem of consciousness', the reality of consciousness is ontologized, and the word 'reality' is added to the subject to somehow juxtapose it with the objective reality. It is impossible to speak of either knowledge or consciousness in the ontological sense and to attribute to them existence as the objective reality. It can be stated that it is the subject that endows objects with a reality - the question of reality and, on the contrary, unreality of a certain object is meaningful only from the perspective of the subject of cognition. The world itself is complete, and only a subject can add non-existence into it (Sartre 2002). Therefore, a subject does not imply a special reality but something that makes it possible to see reality. "For us, there is no way to display subjectivity as part of our worldview, because the subjectivity we are interested is, so to say, is a display itself. Meanwhile, the solution will not imply an attempt to develop a special type of display something like hyper-introspection - but rather in completely quitting the 
attempts to display and simply admitting facts. Facts, in their turn, imply that biological processes generate conscious mental phenomena that are irreducibly subjective” (Searle 2002, 105).

The ephemeral nature of the 'subjective reality' also confirms the impossibility to prove the presence of consciousness in another person - the so-called 'zombie argument' widely discussed in analytic philosophy (Chalmers 1997). Despite the achievements of neurophysiology, which makes it possible to record even the physiological correlates of the self-identification process, any argumentation of the presence of consciousness in another subject inevitably rests on the self-report of this subject. 'The zombie argument' proves only one thing: the elimination of the 'subjective reality' does not change the ontological picture of the world. However, it is equally unreasonable to deny consciousness as a gnoseological phenomenon.

At the same time, it is important to refer to a number of works that note a tendency to debunk the paradigmatic significance of a hard problem, and try to view the 'difficulty' of the latter from aside (Carruthers G., Schier E. 2017, Why are We Still Being Hornswoggled? Dissolving the Hard Problem of Consciousness; McClelland T. 2017, The Problem of Consciousness: Easy, Hard or Tricky?; Bielas J. 2017, The View from Within the Brain: Does Neurofeedback Close the Gap?). This research continues this line and relies on the domestic approach and original methodological developments.

\section{Methods}

As shown by the development of philosophy in the $20^{\text {th }}-21^{\text {st }}$ centuries, which preserved the status of the 'hard' (i.e. intrinsically unsolvable) problem of consciousness for a long time, the existing methods and approaches are not enough, especially in the light of the emergence of new philosophical concepts and achievements of natural sciences related to the study of the human brain and consciousness. Therefore, the authors of this research rely on an essentially new approach formulated as the principle of onto-gnoseological uncertainty (Mamchenkov 2014). 
The principle of onto-gnoseological uncertainty is a philosophical method that lies in the impossibility to separate the problem of an object's essence from the problem of its cognizance, with a recognition of the different natures of these problems and, accordingly, the different natures of the answers to them. In the conceptualization of an object of cognition, two questions are inevitably linked together, in particular, the question about the essence of a given object (the ontological question) and the question of the givenness of an object to the cognizing consciousness (the gnoseological question). This is the inseparability point of ontological and gnoseological inquiries. At the same time, it is impossible to substitute one question with the other since it is impossible to reduce one to the other. Despite the simplicity and obviousness of these statements, there are a lot of examples of this kind of substitutions and reductions in the history of philosophy. It is these moments that cause 'hard' problems.

Does the consistent implementation of the principle of onto-gnoseological uncertainty imply the need to split reality? There is no need to split reality since, firstly, the objective reality and the 'world of consciousness' are displayed as answers to different questions (ontological or gnoseological). Secondly, revealing the irreducibility of the reality of consciousness to the reality of the brain is not something unique to science. The same is true when speaking about the irreducibility of a chemical reality to a physical reality or a social reality to a biological reality. In every layer of reality studied by science, there are laws and principles that are not reducible to 'lower' layers. Moreover, there is a possibility for feedback, i.e. 'higher' layers can influence the functioning of lower layers, for example, the way a person's social activity affects the formation and development of his or her brain (Swaab 2014).

\section{Why the 'Hard Problem of Consciousness' is a pseudo problem?}

The basic result of this research - the most accessible and precise one - is related to the demonstration of the fact that the "hard problem of consciousness', as it appears in modern analytic philosophy, is rather 
a pseudo-problem than a 'hard' problem. To prove this postulate, the authors of this research present four lines of argumentation with each line supplementing the previous one.

1. Uncertainty of concepts. There is no clear-cut definition of consciousness either in philosophy or in scientific discourse. In similar cases, the pseudo-principle of 'family resemblance' (which makes it easy to establish a connection even between a fly and an elephant) is often recalled, which, nevertheless, makes things more obscure. Three related terms are used: psyche, consciousness, and thinking. The meanings of the latter are different but these differences are often not conceptualized. This determines the first 'difficulty' of consciousness, in particular, it may seem that one aspect or interpretation of consciousness has been explained, but then the explanation slips away and dissolves in other aspects. For example, when investigating the connection between 'qualia' and the brain, it is necessary to recall the objective content of consciousness. Trying to examine the intersubjective content of consciousness, it is necessary to speak about the consciousness of a subject endowed with will.

It is generally accepted that the 'consciousness-brain' problem becomes a historical continuation of the research on the relationship between spirit and matter in the modern era. However, the transition of both sides of this relationship is quite obscure. 'Consciousness' and 'spirit' refer to different aspects of the subject matter the authors of this research are interested in. Dubrovsky (2012, 244-245) shows that the other side of the relationship, i.e. the 'physical reality' remains unclarified and blurry in analytic philosophy, which leads to difficulties in such theories. At the same time, the understanding of the multi-dimensionality of reality, which has been studied by various specific sciences, and a clear separation of these dimensions could substantially clarify this problem.

2. Reduction. In analytic philosophy, the problem of consciousness is often reduced to the problem of 'qualia', i.e. the subjective representation of mental processes. However, 'rediscovering' (Searle 2002) or 'explaining' (Dennett 1991) consciousness rather than grasping the indicated connection, one expects to understand the correlation between the objective content of 
consciousness and individual consciousness, invariant laws and meanings inherent in consciousness and specific manifestations of matter.

Suppose that we have found a final answer to the 'hard problem'. Does this mean that it would be possible to understand "Ulysses" after examining Joyce's brain? Or, would it be possible to better understand the principles of quantum mechanics after examining Bohr's brain? The comic nature of these 'achievements' shows the impossibility to completely solve the problem under study within the framework of this paradigm, i.e. the incorrect formulation of the problem. On the other hand, the assumption of giving a solution to the hard problem presupposes that a thorough examination of a person's brain would lead to a perusal of the whole content of a person's consciousness. But this is not yet 'comprehension' of consciousness but simply a fixation of the interrelation between consciousness and the brain, which is obvious even without hard theoretical postulates and is illustrated by a simple blow on the head. Similarly, by deciphering a genome and establishing its interrelation with the characteristics that are encoded to it, one cannot understand and predict the behavior of not only a human being but also of a simpler being (although even with DNA, one should not forget about the complex, non-linear, and even reciprocal connection between the genotype and phenotype (Mednikov 1982)).

3. Elimination of other paradigms. In the analytical tradition, the hard problem of consciousness is viewed as something new and previously unexplored. However, it is necessary to point out that the problem of interaction between various forms of being and levels of matter organization has long been productively discussed in various philosophical areas. Even in particular scientific research, very often there is a need to encounter a supply of questions related to the interaction between various forms of the material world: from the irreducibility of chemism to physical laws (be it classical electro-dynamics or quantum mechanics (Hendry 2006)) to the development of methods for the technical analysis of the dynamics of the cost of various assets on the stock exchanges that make the basis for the earnings of speculators. Why, for example, in the study of biological reality, isn't the irreducibility of biological laws to chemical laws regarded as 'hard' 
and why doesn't this cause a sense of mysteriousness? This irreducibility is quite obvious to a researcher just like the fact that without violating the basic laws of chemistry, biological objects produce novelty in chemistry itself and generate organic substances and 'human' chemistry (Lamza 2014), and the laws by which they function. In the $18-19^{\text {th }}$ centuries, during the period when the classical scientific paradigm was formed in biology, problems of the essence of life and the mysterious 'vital principle', the false acuity of which is very similar to the hard problem of consciousness, were actively discussed in the philosophy of biology. And only against the background of the successes of positive biology, these problems were forgotten and eliminated from philosophical discourse. Nevertheless, these problems remained unsolved in their antinomical formulation. Any attempt to combine philosophical and specific scientific problems and approaches to their solution is initially doomed to failure. Therefore, most likely, in 50 years, today's discourse of analytic philosophers on the nature of consciousness will seem as naive as the $19^{\text {th }}$-century philosophy of life to modern people.

The first consequence of this 'historical blindness' is related to the inattention to the fact that the brain is an object while consciousness is a process. Therefore, it is extremely hard to speak about objects in the language of a process. If, on the contrary, try to establish a correlation of the processes of consciousness not only with the brain but with the entire complex of processes occurring to man (first of all, the ones included in social practice (Metlov 2003)), a hard problem will perhaps lose a significant part of its mysteriousness.

\section{Misunderstanding of the principle of onto-gnoseological uncertainty}

In the explanation of consciousness, objectification is at the heart of the emergence of 'hard problems', i.e. researchers unreasonably objectify consciousness and consider the process as an object. Hereafter, there arises a question of considering consciousness through its material basis, i.e. the reduction of one object to another. If the question initially consisted in 
understanding the material foundations of a certain process, it would imply dependence rather than reduction. In the context of today's widespread understanding, the emergence of an unsolvable problem will be inevitable.

The modern interpretation of the problem of consciousness conceptually goes back to the problem of the soul and body and was formulated by R. Descartes (1989). As demonstrated by T.A. Varkhotov (2003), this problem, in essence, becomes 'hard' due to the transference of gnoseological answers ('certainty' as a criterion of the cognition method) to anthropological questions (the existence of consciousness within the human body). Therefore, the analytical approach will inevitably suffer antinomy.

The second, concomitant result of this research is related to the demonstration of the fact that not only the existing formulations of the problem of consciousness in the analytical tradition give it a status of a pseudo-problem, but, on the whole, the analytical approach to the problem of consciousness will collide with an inevitable antinomy. When studying the nature of consciousness in the analytical paradigm, two opposing and intrinsically contradictory understandings of consciousness are manifested, and the so-called antinomy of consciousness is formed: consciousness as an object and consciousness as a subject.

Perceiving consciousness as an object, we put it in a row with other objects of the external world like a table, a house, etc. Consciousness appears as an object accessible to objective description. Suppose that this approach to the study of consciousness is brought to its logical conclusion, and a complete theory of consciousness has been formed. In this case, both all objects of 'qualia' and subjectively presented properties are available to an external observer. This means that studying the description of consciousness that is in pain, a researcher will also experience pain. If feeling pain remains imperceptible and the research notice only the state of the brain, it would mean that pain 'itself' managed to 'slip away' from research and remained in the 'subjective world', i.e. consciousness (leastways, the consciousness of the researcher) is a subject separated from an object (Tegmark 2015).

Thereat, we postulate consciousness as a subject endowed with private access to the world of 'qualia'. In this case, however, it will be hard for 
subject-consciousness to interact with the surrounding world and to control one's own body. Any interaction between subject-consciousness and the surrounding world draws it into the cause-and-effect conditioning of the objective reality, which tears consciousness out of the allotted subjective world and again places it on a par with the objects of the world. A way out of this kind of objectification would require a dualistic approach, or a boundless expansion of consciousness, subjective idealism. However, modern philosophy does not view these concepts seriously (Kuznetsov 2014).

Is it possible to speak of consciousness as an independent layer of reality? The most important criterion for objective existence implies the selection of invariants, for example, time invariance (maintaining an object's existence for a certain period of time) or subject invariance (the independence of existence from the thinking of a particular subject).

1) The certainty of the existence of the 'subjective reality' at least as a delusion of a subject;

2) the preservation of the unity of apperception as a condition for the unity of the field of experience;

3) the accessibility of both the content of a subject and the mode of its representation to a subject's cognition, as well as the addition of a cognizer to each cognition act.

The above laws are invariants and demonstrate the self-delusion and independence of the reality of consciousness. Consequently, to understand the interrelation between consciousness and bodily processes that form its foundations does not yet mean to understand consciousness (Naidysh 2017).

\section{Conclusions}

Modern studies in the field of the philosophy of consciousness are conducted within a paradigm that contains unavoidable defects and antinomies, which lead to the transformation of the problem of consciousness into a 'hard problem'. The four reasons that make the problem of consciousness not only a 'hard' problem but an unsolvable one (and, in some sense, 'a pseudo-problem') include the uncertainty of concepts; reductionism; 
the elimination of other paradigms, in which the problem of consciousness could be quite simple; and, above all, the misunderstanding of the principle of onto-gnoseological uncertainty.

The elimination of the above-described contradiction is achieved through the realization of its foundation, i.e. the understanding that it is possible to speak of consciousness as an object that has a definite ontological status. In its essence, the subjective reality is the objectification of cognitive activity. Psychology convincingly demonstrates that the 'subjective reality' dissolves with the suspension of cognitive activity (Lebedev 2002). In fact, it is expected to receive an ontological answer to the gnoseological question that arises when studying the 'subjective reality'. This situation is defined by the authors of this research as onto-gnoseological uncertainty.

Realizing the pseudo-nature of the 'difficulty' of the 'hard problem', philosophy should realize the impossibility of combining philosophical and scientific problems, i.e. particular sciences are not able to solve philosophical problems since a similar path leads to reductionism. On the other hand, philosophy, in its turn, should not impose its own vision of certain problems on particular sciences, which is precisely what happens when imposing the division between the subjective and objective reality. The correct implementation of the principle of onto-gnoseological uncertainty with regard to questions of consciousness will allow philosophy to return to the actual philosophical questions. This, first of all, implies the definition of the key categories used by science and, secondly, the definition of the ontological status of different layers of reality and the possibilities of the cognition of these layers.

This article demonstrates that it is impossible to reduce human consciousness to the brain and leads to the recognition that the physical reproduction of the human brain does not yet mean perceiving consciousness in it. Further research on the qualities of the human intellect should be based on a comprehensive view of the work of these qualities and should unite the subjective and objective, as well as personal and social components in the work of consciousness, which presently has critical practical significance in the light of elaborations in the field of artificial intelligence. 


\section{References}

Bielas, Jacek. 2017. “The View from Within the Brain: Does Neurofeedback Close the Gap?” Journal of Consciousness Studies 24 (9-10): 133-155.

Carruthers, Glenn, Schier, Elizabeth. 2017a. "Introduction: The Hard Problem of Consciousness." Topoi 36 (1): 1-3.

Carruthers, Glenn, Schier, Elizabeth. 2017b. "Why are We Still Being Hornswoggled? Dissolving the Hard Problem of Consciousness." Topoi 36 (1): 67-79.

Chalmers, David. J. 1997. The Conscious Mind. In Search of a Fundamental Theory. Oxford: Oxford University Press.

Dennett, Daniel. 1991. Consciousness Explained. Boston: Littl Brown and Co.

Descartes, Rene. 1989. Writings in two volumes. Vol. 1. Moscow.

Dubrovsky, David I. 2012. “The Subjective Reality and the Brain. On the Question about the Half-Century Experience of Developing the 'Hard Problem of Consciousness' in Analytic Philosophy.” In Epistemology: Development Perspectives, by Lektorskiy, V.A., 229-273. Moscow: «Kanon+».

Hendry, Robin F. 2006. “Is There Downward Causation in Chemistry?” In Philosophy of Chemistry, by edited D. Baird et al., 173-191. Boston: Springer.

Horst, Steven. 2014. "Beyond Reduction: From Naturalism to Cognitive Pluralism.” Mind \& Matter 12 (2): 197-244.

Kuznetsov, Anton V. 2014. “Cognitive Research and the Problem of Mental Causality.” Questions of Philosophy 3: 133-143.

Lamza, Lukas 2014. “Six Phases of Cosmic Chemistry.” Hyle - International Journal for Philosophy of Chemistry 20 (1): 165-192.

Lebedev, Vladimir I. 2002. Psychology and Psycholpathology of Loneliness and Group Isolation. Moscow: Unity.

Mamchenkov, Dmitry V. 2014. Objectivity and Historicism. Moscow: RUDN.

Mamchenkov, Dmitry V. 2017. „The ‘Hard Problem’ in Analytic Philosophy.” Newsletter of RUDN. Series "Philosophy” 21 (2): 222-229.

McBride, Raymond. 2014. “Towards a Sublime State of Consciousness.” Journal of Consciousness Studies 21 (11-12): 19-40.

McClelland, Tom. 2017. “The Problem of Consciousness: Easy, Hard or Tricky?” Topoi 36 (1): 17-30.

Mednikov, Boris M. 1982. Axioms of Biology. Moscow: Znanie.

Menon, Sangeetha. 2014. "Beginnings: Biological and Philosophical Accounts of Consciousness.” In Brain, Self and Consciousness, edited by S. Menon, 37-60. New Delhi: Springer. 
Metlov, Vladimir I. 2003. „A Complex Approach to the Problem of Consciousness.” In Proceedings of the Scientific Conference "Philosophy of Consciousness: History and Modernity" dedicated to the memory of A.F. Gryaznov, Professor at Moscow State University (1948-2001), 247-250. Moscow: "Sovremennye Tetradi” Publishing House.

Naidysh, Viacheslav M. 2017. "Mythmaking in the Activity of Consciousness." Questions of Philosophy 5: 26-35.

Russel, Bertran. 1999. Philosophy of Logical Atomism. Tomsk: Vodoley.

Sartre, Jean-Paul. 2002. Being and Nothingness: An Essay on Phenomenological Ontology. Moscow: TERRA-Book Club Republic.

Searle, John. 2002. A Re-Discovery of the Mind. Moscow: Idea-Press.

Smith, Cristopher U. M., Whitaker, Harry. 2014. Brain, mind and consciousness in the history of neuroscience. Dordrecht: Springer.

Smith, Roger. 2015. “History and the hard problem.” Metascience 24 (3): 413-416.

Smythies, John. 2017. “The Role of Brain Mechanisms in the Generation of Consciousness." Journal of Consciousness Studies 24 (1-2): 254-263.

Swaab, Dick. 2014. We are Our Brains: From the Womb to Alzheimer's. St. Petersburg: Ivan Limbakh Publishing House.

Tegmark, Max. 2015. “Consciousness as a State of Matter.” Chaos, Solitons \& Fractals 76: 238-270.

Tsou, Jonathan Y. 2013. “Origins of the Qualitative Aspects of Consciousness: Evolutionary Answers to Chalmers' Hard Problem.” In Origins of Mind, edited by Liz Swan, 259-269. Dordrecht: Springer.

Varkhotov, Taras A. 2003. "Cartesian Anthropology as the Epistemological Framework of Modern Philosophy of Consciousness." In Proceedings of the Scientific Conference "Philosophy of Consciousness: History and Modernity" dedicated to the memory of A.F. Gryaznov, Professor at Moscow State University (1948-2001), 30-41. Moscow: "Sovremennye Tetradi” Publishing House.

Wittgenstein, Ludwig. 1994. “Philosophical Studies.” In Philosophical Works. Moscow: Gnosis. 